\title{
Multidrug-Resistant Infections Among Hospitalized Adults With Community-Acquired Pneumonia In An Indonesian Tertiary Referral Hospital
}

This article was published in the following Dove Press journal: Infection and Drug Resistance

\section{Abdul KR Purba (D) ${ }^{1-5}$ Purwantyastuti Ascobat ${ }^{4}$ Armen Muchtar ${ }^{4}$ Laksmi Wulandari (iD ${ }^{6}$ Alfian Nur Rosyid (iD ${ }^{6}$ Priyo Budi Purwono (iD) ${ }^{7}$ Tjip $S$ van der Werf (iD) ${ }^{8}$ Alex W Friedrich (iD ${ }^{2}$ Maarten J Postma 1,3,5,9}

'Unit of Global Health, Department of Health Sciences, University of Groningen, University Medical Center Groningen, Groningen, The Netherlands; ${ }^{2}$ Department of Medical Microbiology, University of Groningen, University Medical Center Groningen, Groningen, The Netherlands; ${ }^{3}$ Department of Pharmacology and Therapy, Faculty of Medicine, Universitas Airlangga - Dr. Soetomo Hospital, Surabaya, Indonesia; ${ }^{4}$ Department of Pharmacology and Therapeutics, Faculty of Medicine, Universitas Indonesia, Jakarta, Indonesia; ${ }^{5}$ Unit of PharmacoTherapy, Epidemiology and -economics (PTE2), Department of Pharmacy, Faculty of Science and Engineering, University of Groningen, Groningen, The Netherlands; ${ }^{6}$ Department of Pulmonology and Respiratory Medicine, Faculty of Medicine, Universitas Airlangga - Dr. Soetomo Hospital, Surabaya, Indonesia; ${ }^{7}$ Department of Microbiology, Faculty of Medicine, Universitas Airlangga - Dr. Soetomo Hospital, Surabaya, Indonesia; ${ }^{8}$ Department of Internal Medicine, University of Groningen, University Medical Center Groningen, Groningen, The Netherlands; 'Department of Economics, Econometrics and Finance, Faculty of Economics \& Business, University of Groningen, Groningen, The Netherlands

Correspondence: Abdul KR Purba Universitair Medisch Centrum Groningen, Hanzeplein I, Groningen 9700RB, The Netherlands

Tel +3I 697524 II

Email khairul_purba@fk.unair.ac.id
Objectives: To evaluate the clinical and microbiological appearance among hospitalized pneumonia patients focusing on resistance and risk factors for mortality in a referral hospital. Patients and methods: The study was an observational retrospective study on patients with CAP from 2014 to 2016 at Dr Soetomo referral hospital of Surabaya, Indonesia. All positive cultures with antimicrobial susceptibility results from blood and respiratory specimens were included. Patients infected with drug-susceptible pathogens and MDR organisms were also assessed in terms of clinical characteristics, day-3 clinical improvement, and 14day mortality.

Results: Of 202 isolates, 181 possessed antimicrobial susceptibility data. S. pneumoniae was the most prevalent pathogen causing CAP (18.3\%). Most patients were empirically treated with ceftriaxone $(n=75 ; 41.4 \%)$. Among beta-lactam antibiotics, the susceptibility to the third-generation cephalosporins remained relatively high, between $67.4 \%$ and $82.3 \%$, compared with the other beta-lactams such as amoxicillin/clavulanate and ampicillin/sulbactam (a sensitivity rate of $36.5 \%$ and 47.5 , respectively). For carbapenem antibiotics, imipenem and meropenem susceptibility was $69.6 \%$ and $82.3 \%$ respectively. Approximately $22 \%$ of isolates were identified as MDR that showed significant differences in clinical outcomes of 14-day mortality rates $(\mathrm{p}<0.001)$. Notably, patients with day-3 improvement had a lower risk of mortality $(\mathrm{OR}=0.06 ; 95 \% \mathrm{CI}=0.02-0.19)$.

Conclusion: One-fifth of causative agents among hospitalized CAP cases were identified as MDR organisms. The pathogens of MDR and non-MDR CAP remain susceptible to the third-generation cephalosporins. Together with additional consideration of culture findings and Pneumonia Severity Index (PSI) assessment, a 3-day clinical assessment is essential to predict the prognosis of 14-day mortality.

Keywords: gram-negative bacteria, pneumonia, microbial sensitivity tests, developing country, day-3 improvement

\section{Introduction}

Community-acquired pneumonia (CAP) is mostly due to bacterial infections which are specifically recognized as community-acquired bacterial pneumonia (CABP). ${ }^{1}$ All guidelines agree that at least one empiric antibiotic is needed especially for hospitalized patients. ${ }^{2-5}$ The international association, Community-Acquired Pneumonia Organization (CAPO) reported that between 2001 and 2011 mortality rates of the infection reached 7.3\%, 9.1\%, and $13.3 \%$, in North America, Europe, and South America respectively. ${ }^{6}$ In 2013, the 
incidence rates of CAP in low-middle-income countries (LMICs) such as Indonesia was $4.5 \%$ and remained high at $4 \%$ in $2018 .^{7,8}$ No available published data relates to the mortality of the disease in the country.

In order to achieve the appropriate therapeutics, updated epidemiology of antimicrobial resistance is required to support therapeutic guidelines. International associations such as the British and American Thoracic Societies (BTS and ATS) have indicated that gram-positive bacteria are the most widespread causes of CAP. ${ }^{3,5}$ Nevertheless, the guidelines reflected studies published in 2003 from high-income countries where Streptococcus pneumoniae was identified as the dominant pathogen causing $\mathrm{CAP}^{9}$ and beta-lactam antibiotics were recommended as the preferred treatment. ${ }^{2,3,5}$

Studying CAP among LMICs, etiology of the disease was generally problematic. Less restriction of antibiotic use in the community and the differences in the healthcare systems in LMICs may impact on the existence of MDR pathogens. $^{10,11}$ Indiscriminate use of antimicrobials, not guided by microbiological guidance, generally results in the emergence of antimicrobial resistance, both for individual patients and at the community level. The World Health Organization (WHO) has labeled the use of antiinfectives with a high warning in the global report on surveillance of antimicrobial resistance. ${ }^{12}$ Antibiotic resistance leads to long hospitalization periods, treatment failure, and a high economic burden. ${ }^{13,14}$

Local epidemiology may vary by country, and therefore local protocols and guidelines should be based on local prevalence and susceptibility data, which will guide appropriate use of antibiotics, thereby improving outcomes, reducing the duration of hospitalization and preventing the emergence of antimicrobial resistance with inherent increased costs. The local epidemiology of CAP etiology could support stakeholders to develop strategies on prescribing to control the resistance in the community and in hospitals. The major gap between the guidelines' review and the local patterns in terms of the pathogens causing CAP may drive several healthcare centers to implement the use of different antibiotics as alternative treatments to the resistance of community infections. ${ }^{15}$ Notably, Acinetobacter baumannii infections associated with CAP contributed to multidrug resistance (MDR) and has led to high mortality in Asia Pacific countries. ${ }^{16-18}$ In Indonesia, the data on recent CAP etiology and MDR is limited. This study aims to analyze on the etiology of CAP and MDR-CAP, with a focus on the rate of antibiotic resistance and the risk factors for CAP-related mortality in an Indonesian tertiary referral hospital.

\section{Materials And Methods}

\section{Study Design And Ethical Approval}

We performed a retrospective observational study involving adult patients newly admitted to hospital with CAP. We collected the data from Dr. Soetomo Hospital, a large tertiary referral and academic hospital with approximately 1,514 beds in East Java, Indonesia. The study proposal was submitted to the research and development center of Dr. Soetomo Hospital. The study was approved by the ethical committee of Dr. Soetomo Hospital, Surabaya, Indonesia, with letter no. 480/Panke.KKE/X/2014). The committee decided that the study did not need a review in terms of patient consent because of the retrospective observational design. The study complies with the agreement on Indonesia research conduct and the Declaration of Helsinki (Ethical Principles for Medical Research Involving Human Subjects version 2013). ${ }^{19}$ The data was obtained from the medical record department with patient anonymity and confidentiality maintained.

\section{Patients And Treatment}

The data was gathered from the inpatient registry database with an International Classification of Diseases (ICD) code of 10 J.18.x from 2014 to 2016 . The inclusion criteria of the study included all inpatients aged 20 years or above with CAP as a primary diagnosis. The respiratory tract sputum or blood samples were collected before the start of empirical antimicrobial treatment. We only included patients who met the diagnosis based on the national guidelines for CAP from the Indonesian Society of Respirology. ${ }^{20}$ The diagnosis was based on new pulmonary infiltrates on the chest radiograph, progressive cough, purulent sputum, fever $\left(>38^{\circ} \mathrm{C}\right)$, and at least two additional symptoms consisting of increased dyspnea, pleuritic pain, leukocytosis $\left(>10,000 / \mathrm{mm}^{3}\right)$ or leukopenia $\left(<4,500 / \mathrm{mm}^{3}\right)$, lung consolidation suggested by dullness to percussion of the chest, and abnormal chest auscultation findings including crepitations, crackles, or rhonchi. We excluded patients who had received parenteral antibiotics $48 \mathrm{hrs}$ before hospitalization, those with negative cultures, and those hospitalized in other healthcare facilities more than 14 days within 30 days before the current hospital admission. Regarding CAP diagnosis, a pulmonologist made a visit at the first $24-48 \mathrm{hrs}$ of admission to clarify the diagnosis. Therefore, we also excluded patients who died 
within $24 \mathrm{hrs}$ after admission. In the hospital, patients received empirical antibiotics according to a guideline of the Indonesian Society of Respirology for CAP within $24 \mathrm{~h}$ of admission. To ensure adequate identification of etiology among CAP patients who had culture samples obtained after empirical antibiotic administrations, and also excluded any patients whose culture samples were obtained more than $48 \mathrm{hrs}$ after admission. The description of the management of hospitalized CAP patients is presented in Table 1.

\section{Microbiological Evaluation}

Bacterial culture from patients' sputum and blood samples collected within the first $24 \mathrm{~h}$ of admission was tested for microbiological evaluation. In terms of quality, the sputum was considered to be acceptable where it contained $>25$ granulocytes and $<10$ squamous epithelial cells per low-power field (x10). ${ }^{21}$ The eligible sputum specimen was subsequently submitted to species identification and susceptibility testing. We assessed the susceptibility to the available antimicrobial agents in the hospital including amoxicillin-clavulanate (AMC), ampicillin-sulbactam (SAM), ticarcillin-clavulanate (TIC), piperacillin-tazobactam (PIP), cefazolin (CFZ), ceftazidime (CAZ), cefoperazone-sulbactam (CFP, trimethoprim-sulfamethoxazole (STX), ciprofloxacin (CIP), levofloxacin (LVX), moxifloxacin (MXF), imipenem (IPM), and meropenem (MEM). Testing of amikacin (AMK) and gentamicin (GEN) susceptibilities were conducted only for Gram-negative bacteria (GNB). In particular, vancomycin susceptibility was tested on Gram-positive bacteria (GPB) only. Pathogens were defined as multidrug-resistant (MDR) if the organisms were resistant to at least one single agent in three or more groups of antimicrobial agents. $^{22}$ The antimicrobial susceptibility pattern was reported as sensitive (S), intermediate-susceptible (I), or resistant $(\mathrm{R})$ for each isolated species based on the microbiology department of the hospital using the Clinical and Laboratory Standards Institute (CLSI) criteria. $^{23}$

\section{Clinical Evaluation}

To explore the impact of MDR infections compared to nonMDR infections, we compared baseline demographics, physical examination, laboratory and radiology findings, comorbidities, pneumonia severity index (PSI) scores, the need for intensive care, the empirical antimicrobial treatment given, length of stay (LoS), clinical improvement on day-3, and 14day mortality. On day-3 of hospital admission, we assessed the following clinical symptoms comparing with baseline on admission: mental status; respiratory rate (n: $12-24 / \mathrm{min}$ ); heart rate (n: $\leq 100$ beats/min); systolic blood pressure (cut-off $\geq 90 \mathrm{mmHg}$ ); arterial oxygen saturation (cut-off: $\geq 90 \%$ ); oral intake ability; temperature $\left(<38.5^{\circ} \mathrm{C}\right)$; and leucocyte count $\left(3.5-10.5 \times 10^{9} / \mathrm{L}\right){ }^{3}$ PSI is a validated scoring system representing the baseline physiologic parameters and pre-existing comorbidities adding up a total score of 19 factors; the total score is categorized into five classes: class I $(<51)$, class II ( $51-$ $70)$, class III (71-90), class IV (91-130), and class V (>130). ${ }^{24}$

\section{Statistical Analysis}

The statistical analyses were performed using SPSS (SPSS 23, University of Groningen, Netherlands). For categorical data, chi-square (or Fisher exact test with more than $20 \%$ cells with

Table I Indonesian Guideline For CAP Patients

\begin{tabular}{|c|c|}
\hline Patient Care & The Strategies: \\
\hline Wards & $\begin{array}{l}\text { One of the following options: } \\
\text { I. Beta-lactam iv + beta-lactamase inhibitor iv } \\
\text { 2. The second and third generation of cephalosporins iv } \\
\text { 3. Respiratory fluoroquinolone iv } \\
\text { Macrolide (additional antibiotic when atypical infections identified) }\end{array}$ \\
\hline Intensive care & $\begin{array}{l}\text { No pseudomonal infection: } \\
\text { I. The third-generation of cephalosporin iv + macrolide } \\
\text { When a pseudomonal infection presents, one of the following options: } \\
\text { I. Anti-pseudomonal cephalosporin iv } \\
\text { 2. Carbapenem iv + anti-pseudomonal antibiotic iv } \\
\text { 3. Aminoglycoside iv } \\
\text { If there is an atypical infection, using the following three-drug combination: } \\
\text { Anti-pseudomonal cephalosporin iv (or carbapenem iv) + macrolide (or respiratory fluoroquinolone iv) + aminoglycoside iv }\end{array}$ \\
\hline
\end{tabular}

Note: Adapted from Indonesian Society of Respirology. Guideline for diagnosis and management of community pneumonia in Indonesia[Perhimpunan Dokter Paru Indonesia. Pneumonia komuniti: pedoman diagnosis \& penatalaksanaan di Indonesia]. 2003. Available: http://www.klikpdpi.com/konsensus/konsensus-pneumoniakom/pnkomuniti.pdf. ${ }^{20}$ 
expected values less than 5) were used. For continuous variables, the distribution of data was first tested. Data with normal distribution were provided as mean and standard deviation (SD). Otherwise, the data were expressed as median with 25 th and 75 th percentiles. The differences among the empirical antibiotics on all analyses were considered statistically significant at $\mathrm{p}$-value $<0.05$. Multivariate analysis was used to determine whether there was an independent association of three risk factors of 14-day mortality. First, the host factors analyzed were gender, age (60 or above), cardiovascular disease, neoplasm, diabetes mellitus (DM), liver diseases, renal insufficiency, since those comorbidities were independent risk factors of mortality. ${ }^{25,26}$ Also, PSI class 3 or above, and day-3 improvement were integrated assessments considered in the analyses. Second, the pathogen factor of drug-susceptible or MDR. Third, the treatment: combinations of empirical antimicrobials compared to a single antimicrobial agent. Each risk factor was presented as an odds ratio (OR) with a confidence interval (CI) of $95 \%$ where the value of $95 \%$ CI not including 1 indicated no statistical difference.

\section{Results}

\section{Pathogen Characteristics And}

\section{Antimicrobial Susceptibility}

Two hundred and two bacterial isolates were collected from 181 patients. Each patient had one result of antimicrobial susceptibility testing. The identified causative agents are shown in Table 2. Most culture specimens were collected

Table 2 Etiology Characteristics ( $n=202$ Isolates)

\begin{tabular}{|c|c|c|c|c|c|}
\hline Bacterial Agents & $\mathbf{N}$ & Percentage & Blood Culture & Sputum Culture & MDR-CAP \\
\hline \multicolumn{6}{|l|}{ Single-agent } \\
\hline A. baumannii & 27 & 13.4 & & 27 & 13 \\
\hline Enterobacter spp & 10 & 5.0 & & 10 & 3 \\
\hline E. coli & 10 & 5.0 & & 10 & I \\
\hline K. pneumoniae & 25 & 12.4 & & 25 & 9 \\
\hline P. aeruginosa & 18 & 8.9 & & 18 & 8 \\
\hline S. aureus & 9 & 4.5 & & 9 & 2 \\
\hline S. non-haemolyticus & 4 & 2.0 & & 4 & \\
\hline S. pneumoniae & 26 & 12.9 & & 26 & 1 \\
\hline S. viridans & 31 & 15.3 & & 31 & \\
\hline \multicolumn{6}{|l|}{ Mixed-agents } \\
\hline A. baumannii & I & 0.5 & I & & \\
\hline + M. tuberculosis & 1 & 0.5 & & I & \\
\hline Enterobacter spp & I & 0.5 & I & & 1 \\
\hline$+H$. influenzae & I & 0.5 & & I & \\
\hline K. pneumoniae & 1 & 0.5 & I & & I \\
\hline + M. tuberculosis & 1 & 0.5 & & I & \\
\hline K. pneumoniae & I & 0.5 & I & & 1 \\
\hline$+H$. influenzae & I & 0.5 & & I & \\
\hline P. aeruginosa & I & 0.5 & & I & 1 \\
\hline + Pantoe agglomerans & 1 & 0.5 & I & & \\
\hline S. pneumoniae & 1 & 0.5 & & I & \\
\hline + Cronobacter sakazakii & 1 & 0.5 & & I & \\
\hline S. pneumoniae & 4 & 2.0 & & 4 & \\
\hline$+H$. influenzae & 4 & 2.0 & & 4 & \\
\hline S. pneumoniae & 4 & 2.0 & & 4 & I \\
\hline + M. tuberculosis & 4 & 2.0 & & 4 & \\
\hline S. pneumoniae & 2 & 1.0 & & 2 & \\
\hline + Staphyloccus spp (coagulase negative) & 2 & 1.0 & & 2 & \\
\hline S. viridans & 2 & 1.0 & & 2 & I \\
\hline + M. tuberculosis & 2 & 1.0 & & 2 & \\
\hline S. viridans & 3 & 1.5 & & 3 & I \\
\hline$+H$. influenzae & 3 & 1.5 & & 3 & \\
\hline
\end{tabular}


from the respiratory tract $(97.5 \%)$. The dominant pathogen was $S$. pneumoniae (18.3\%) followed by S. viridans (17.8\%), A. baumannii (13.9\%), K. pneumoniae (13.4\%), P. aeruginosa (9.4\%), Enterobacter spp. (5.4\%), E. coli (5\%), S. aureus (4.5\%). Isolates of $H$. influenzae (4.5\%), M. tuberculosis (4\%), S. non-haemolyticus (2\%), and CoagulaseNegative Staphylococci (1\%) were identified as mixed pathogens. Of all identified bacteria, 44 were MDR organisms (22\%), of which A. baumannii demonstrated to be the most prevalent pathogen among MDR isolates (6.4\%) (Table 2). Ciprofloxacin and amoxicillin/clavulanic had the lowest potential efficacy of antibiotics against MDR organisms (Figure 1). In general, with reference to all pathogens $(\mathrm{n}=181)$, the third-generation cephalosporins had fair sensitivity at $67.4 \%, 70.2 \%, 70.7 \%$, and $82.3 \%$ for cefotaxime, ceftriaxone, ceftazidime, cefoperazone respectively. Vancomycin appeared susceptible to all GPB. Likewise, among GNB, susceptibility was $84.2 \%$ for amikacin and $78.9 \%$ for gentamicin (Table 3 ).

\section{The Impact Of MDR Infections On Clinical Manifestation}

A total of 181 patients satisfied the study criteria. Patients were predominantly male $(64.6 \%)$ with a mean age of 56.5 years. Predominant complaints during hospital admission were dyspnea (98.3\%) and fever (96.1\%). Another common clinical presentation was cough and chest discomfort, documented at $73.5 \%$ and $21 \%$, respectively. The most common comorbidity was diabetes mellitus (28.2\%) followed by neoplasm $(25.4 \%)$, cardiovascular disease $(11.6 \%)$, renal insufficiency $(17.1 \%)$ and hepatic disorder (7.2\%) (Table 4).

Within non-MDR infections, most patients clinically manifested with PSI class III (49.6\%). In contrast, patients with MDR infections were mostly in PSI class IV (43.2\%). Of 44 patients with MDR, 22.7\% needed intensive care, which was a significantly higher proportion than those with non-MDR (13.1\%). Also, the most common antibiotics for empirical treatment either as single or combined use were ceftriaxone $(49.2 \%)$, ceftazidime $(39.8 \%)$, and levofloxacin $(27.6 \%)$. The use of empirical antibiotic combination was higher in patients with MDR (34.1\%) compared to non-MDR infections (10.9\%).

Bivariate comparisons of patient characteristics and the clinical outcomes between non-MDR and MDR infections are presented in Table 4. The clinical characteristics and clinical outcomes were significantly different with respect to neoplasm (17.5\% vs 50\%), DM (24.1\% vs $40.9 \%$ ), PSI class I to $\mathrm{V}$ (p-value $=0.003)$, day-3 improvement $(55.5 \%$ vs $11.4 \%$ ) and 14 -day mortality (21.9\% vs $26.8 \%)$. The median duration of hospitalization between the two groups was not significantly different (11.5 vs $12.6 \mathrm{~d}$ ).

\section{The Risk Factors Of Mortality}

Multivariate analysis of variables considered relevant to the outcome of 14-day mortality is presented in Table 5. Among patient factors, patients with neoplasm $(\mathrm{OR}=2.76$;

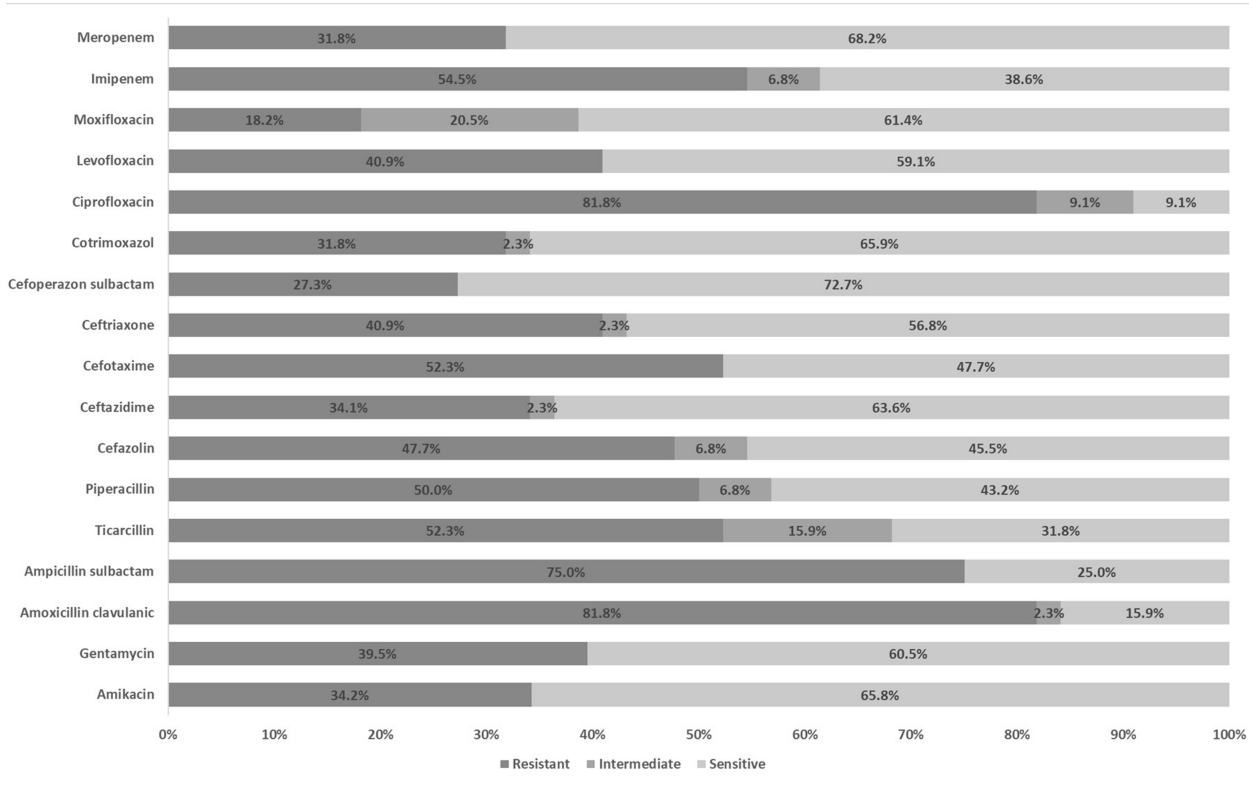

Figure I Resistance, intermediate, and sensitivity rates of multidrug-resistant agents causing hospitalized community-acquired pneumonia. 


\begin{tabular}{|c|c|c|c|c|c|c|c|}
\hline 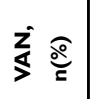 & $\mathbb{z} \mathbb{z}$ & $\mathbb{z} \mathbb{z}$ & $\mathbb{z} \mathbb{z}$ & $\mathbb{z} \mathbb{z} \mathbb{z}$ & $\mathbb{z} \mathbb{z} z$ & $\stackrel{\frac{o}{\sigma}}{\sigma} \circ 0$ & $\stackrel{\frac{\delta}{\sigma}}{a} 00$ \\
\hline$\stackrel{\sum}{\Sigma} \underset{\Sigma}{\stackrel{\varpi}{\Sigma}}$ & 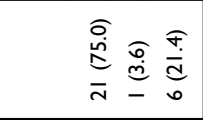 & 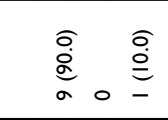 & 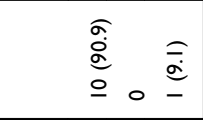 & 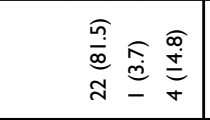 & 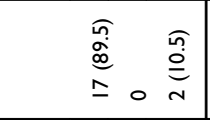 & 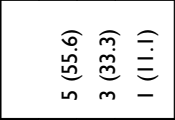 & 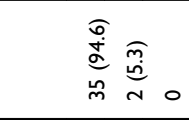 \\
\hline 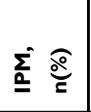 & 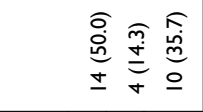 & 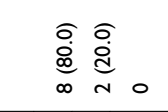 & 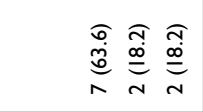 & 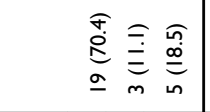 & 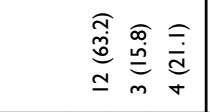 & 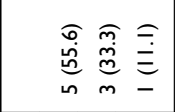 & 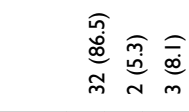 \\
\hline 晟 & 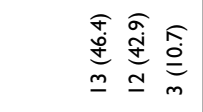 & 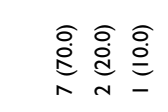 & 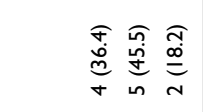 & 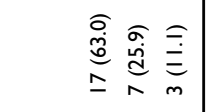 & 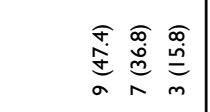 & 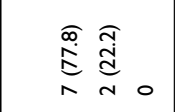 & 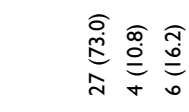 \\
\hline 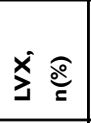 & 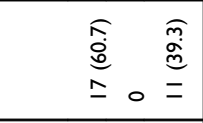 & 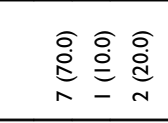 & 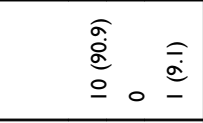 & 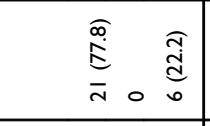 & 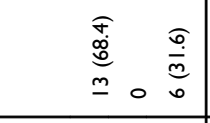 & 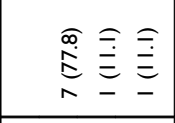 & 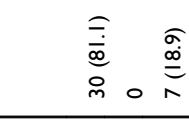 \\
\hline 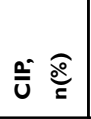 & 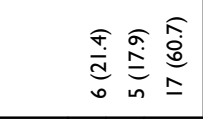 & 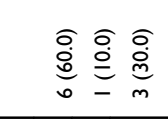 & 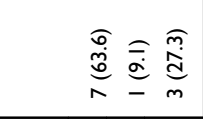 & 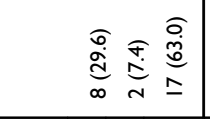 & 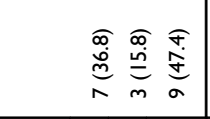 & 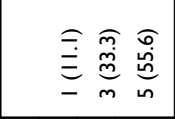 & 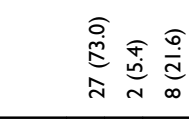 \\
\hline 攴 & 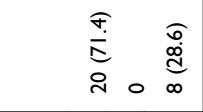 & 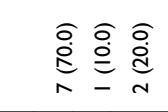 & 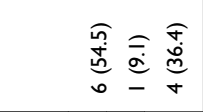 & 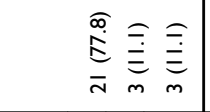 & 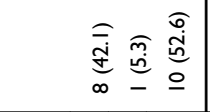 & 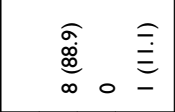 & 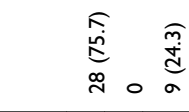 \\
\hline 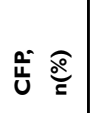 & 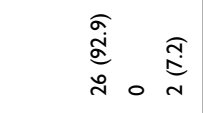 & 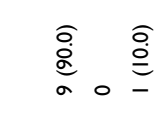 & $\begin{array}{ll}\frac{a}{\dot{a}} & \widehat{\bar{a}} \\
\stackrel{0}{0} & 0\end{array}$ & 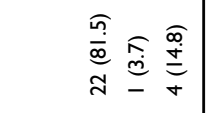 & 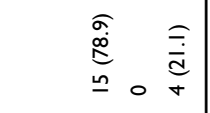 & 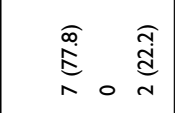 & 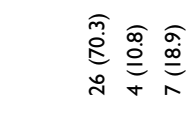 \\
\hline 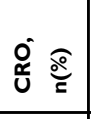 & 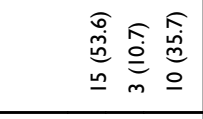 & $\begin{array}{ll}\widehat{a} & \\
\stackrel{0}{0} & 0 \\
\wedge & 0 \\
\end{array}$ & $\begin{array}{lll}\underset{d}{d} & \widehat{\widetilde{R}} \\
\infty & 0 & \stackrel{d}{d} \\
\end{array}$ & 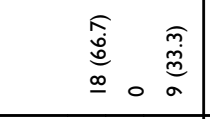 & 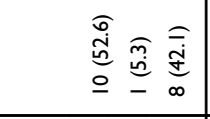 & 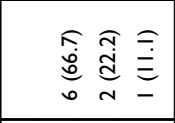 & 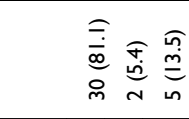 \\
\hline 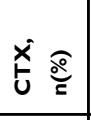 & 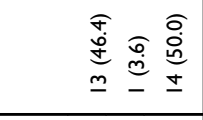 & 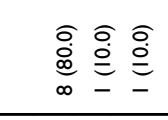 & 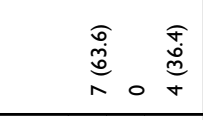 & 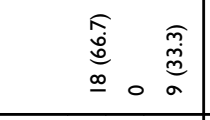 & $\begin{array}{lll}\substack{\hat{i} \\
\hat{n}} & \widehat{\bar{y}} \\
= & 0 & \infty \\
\end{array}$ & 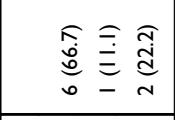 & 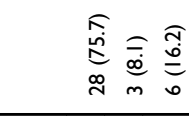 \\
\hline 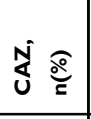 & 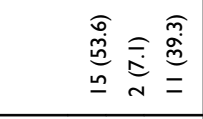 & 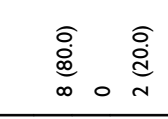 & 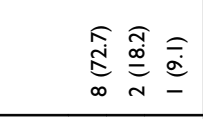 & 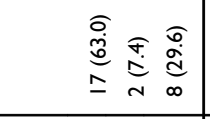 & 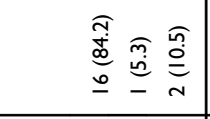 & 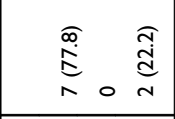 & 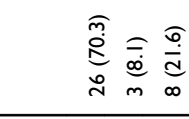 \\
\hline Uू & 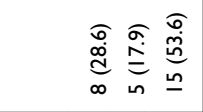 & 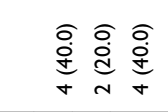 & 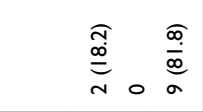 & 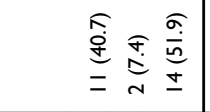 & 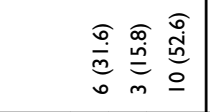 & 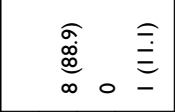 & 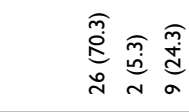 \\
\hline 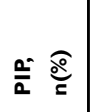 & 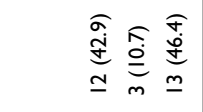 & 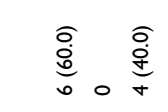 & 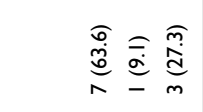 & 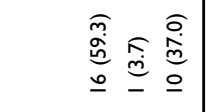 & 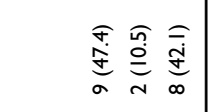 & 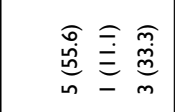 & 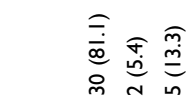 \\
\hline 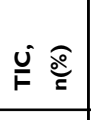 & 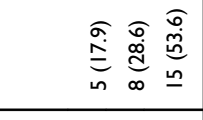 & 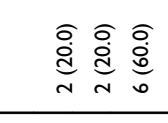 & 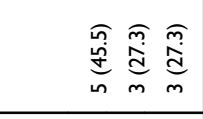 & 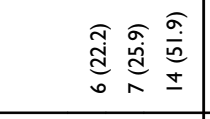 & 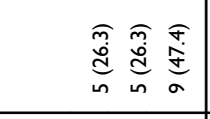 & 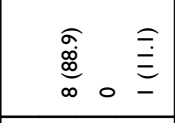 & 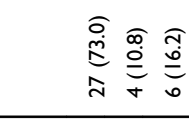 \\
\hline 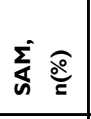 & 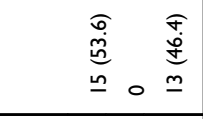 & 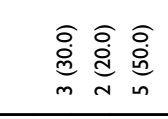 & 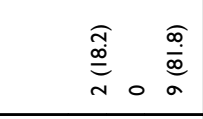 & 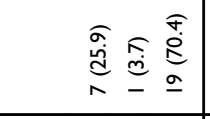 & 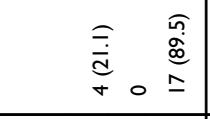 & 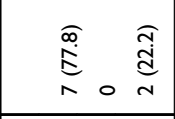 & 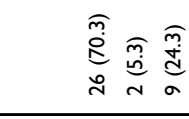 \\
\hline 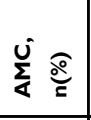 & 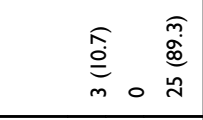 & 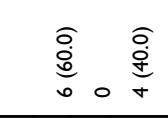 & 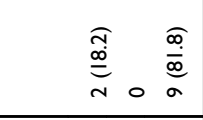 & 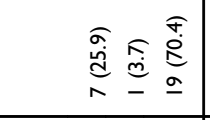 & 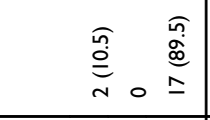 & 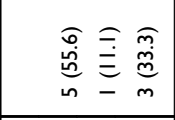 & 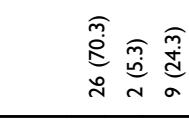 \\
\hline ż & 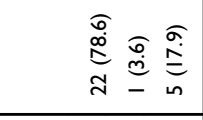 & 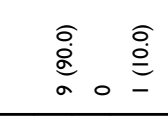 & 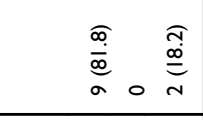 & 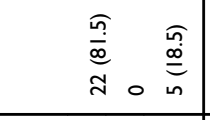 & 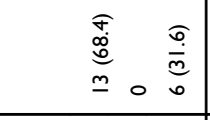 & $\mathbb{z} \mathbb{z} \frac{s}{z}$ & 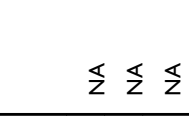 \\
\hline 芝 & 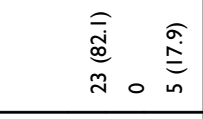 & 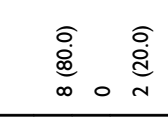 & 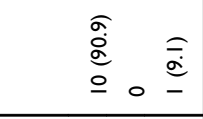 & 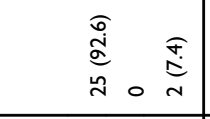 & 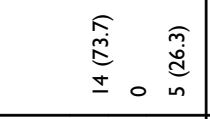 & $\mathbb{z} \mathbb{z}$ & $\S \leftleftarrows \mathbb{z}$ \\
\hline 营 & 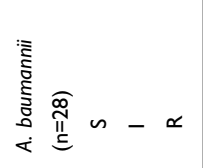 & 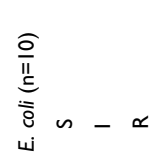 & 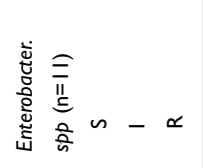 & 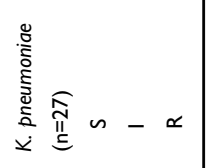 & 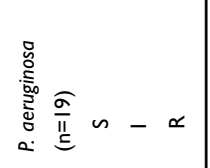 & 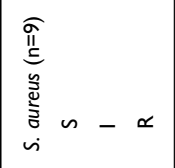 & 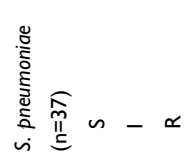 \\
\hline
\end{tabular}




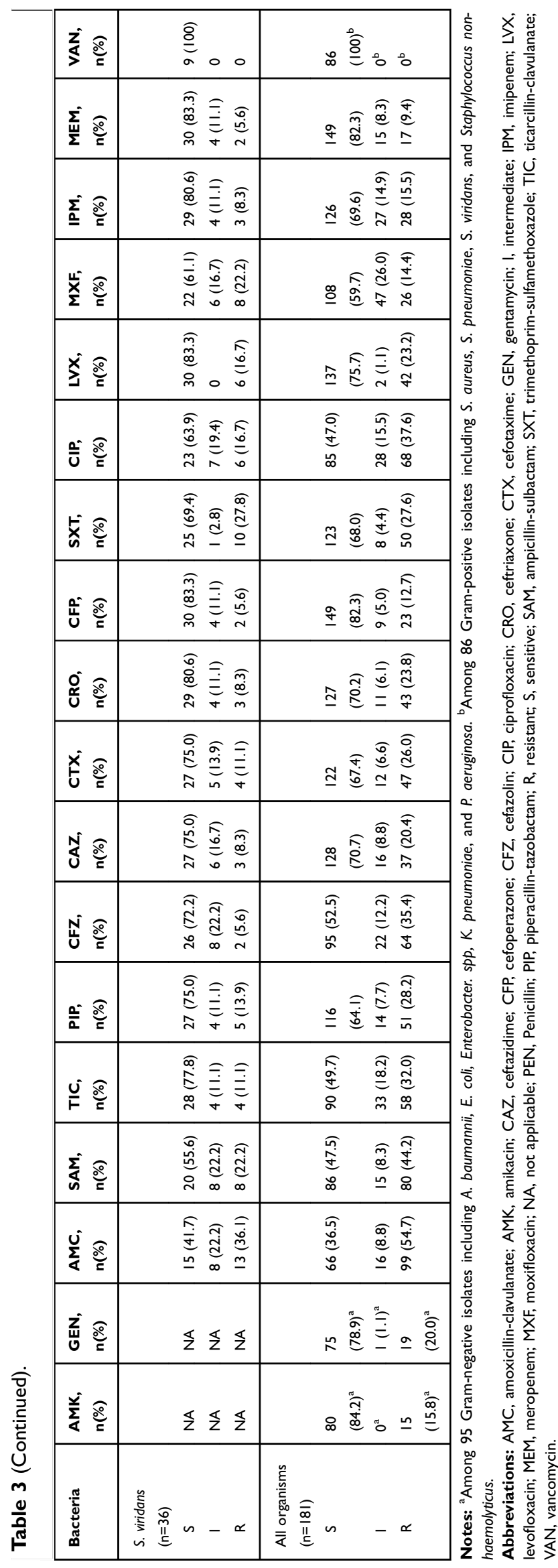

95\% CI $=1.03-7.36)$ and those with PSI class III or above $(\mathrm{OR}=9.19 ; \quad 95 \% \quad \mathrm{CI}=1.51-55.89)$ had a significantly increased risk of mortality. Clinical improvement at day3 appeared to provide protection, with decreased mortality; $\mathrm{OR}=0.06 ; 95 \% \mathrm{CI}=0.02-0.19$.

\section{Discussion}

Our study suggests that CAP in the study area is not only caused by GPB but also frequently by GNB. The pathogens generally remained sensitive to third-generation cephalosporins which are also recommended by the local guideline. Microbiological culturing of sputum and blood provided clinically relevant information concerning the identity of pathogens with their susceptibility to antimicrobials. Clearly amoxicillin and penicillin even if combined with a beta-lactamase inhibitor are no longer effective in our setting. Our results support a strategy to avoid these agents for patients admitted to hospital with CAP, particularly in LMICs. Empirical treatment for CAP should indeed be guided by culture data that are locally obtained and susceptibility testing. ${ }^{27,28}$

In our study, $S$. pneumoniae was the most common pathogen, with conserved penicillin susceptibility. A study on S. pneumoniae infections in 13 Asian countries reported that the incidence of the pathogen was high at $29.2 \%$ among CAP in Pan-Asia. ${ }^{29}$ Mixed pathogens are an important consideration since they may lead to delayed response or even a lack of clinical improvement. Like the systematic review conducted on studies in Asia, our findings also revealed mixed infections with $S$. pneumoniae and $M$. tuberculosis or $H$. influenzae. ${ }^{30,31}$ In contrast to community-acquired viridans streptococcal pneumonia, our study pointed out that the organism had low sensitivity to amoxicillin/clavulanate acid. The mechanism of resistance to penicillin among $S$. viridans isolates seems to be through alteration of the penicillin-binding proteins (PBPs), especially among patients with underlying diseases. ${ }^{32}$ The change on the site of PBPs generates inadequate binding not only for penicillin but also for other $\beta$-lactams including cephalosporins. ${ }^{33,34} \mathrm{~S}$. viridans organisms in our study might also represent normal microbial flora as colonization in the upper-respiratory tract. ${ }^{35,36}$ However, invading to lower-respiratory tract or bloodstream, S. viridans could lead to serious infections. In previous clinical reports, S. viridans could cause complications of parapneumonic effusion or empyema in patients with CAP. ${ }^{37-39}$ One of the important organisms commonly encountered among those causing pneumonia is 
Table 4 Comparisons Of Clinical Characteristics Between Non-MDR and MDR

\begin{tabular}{|c|c|c|c|c|}
\hline Clinical Characteristics & All Patients $(n=181)$ & Non-MDR $(n=137)$ & MDR $(n=44)$ & p-Value \\
\hline \multicolumn{5}{|l|}{ Gender } \\
\hline Male, n (\%) & $117(64.6)$ & $84(61.3)$ & $33(75.0)$ & 0.099 \\
\hline Female, $\mathrm{n}(\%)$ & 64(35.4) & $53(38.7)$ & II (25.0) & \\
\hline Age (years), mean (SD) & $56.5(12.8)$ & $55.7(\mid 2.6)$ & $59.0(13.5)$ & 0.157 \\
\hline \multicolumn{5}{|l|}{ Chief complaints at hospital admission } \\
\hline Fever, n (\%) & $174(96.1)$ & $130(94.9)$ & $44(100.0)$ & 0.137 \\
\hline Cough, n (\%) & $133(73.5)$ & $100(75.2)$ & $33(24.8)$ & 0.793 \\
\hline Dyspnea, n (\%) & I78(98.3) & 134(97.8) & $44(100.0)$ & 0.431 \\
\hline Chest discomfort, $\mathrm{n}(\%)$ & $38(21.0)$ & $26(19.0)$ & $12(27.3)$ & 0.240 \\
\hline $\mathrm{RR}(/ \mathrm{min})$, median $\left(\mathrm{P}_{25}-\mathrm{P}_{75}\right)$ & $26(22-28)$ & $24(22-28)$ & $26(22.5-28)$ & 0.210 \\
\hline Body temperature $\left({ }^{\circ} \mathrm{C}\right)$, median $\left(\mathrm{P}_{25}-\mathrm{P}_{75}\right)$ & $37.0(36.7-37.8)$ & $37.0(36.7-37.8)$ & $37.0(36.7-37.7)$ & 0.756 \\
\hline Blood leucocytes $\left(\right.$ per $\left.\mathrm{mm}^{3}\right)$, median $\left(\mathrm{P}_{25}-\mathrm{P}_{75}\right)$ & $14,865(11,450-18,650)$ & $15,000(11,500-18,200)$ & $14,075(\mid 1,155-19,700)$ & 0.750 \\
\hline SBP $(\mathrm{mmHg})$, median $\left(\mathrm{P}_{25}-\mathrm{P}_{75}\right)$ & $120(\mid 10-130)$ & $110(110-130)$ & $120(\mid 10-140)$ & 0.253 \\
\hline DBP $(m m H g)$, median $\left(P_{25}-P_{75}\right)$ & $70(70-80)$ & $70(70-80)$ & $75(70-80)$ & 0.929 \\
\hline \multicolumn{5}{|l|}{ Arterial blood gas } \\
\hline $\mathrm{pH}$, median $\left(\mathrm{P}_{25}-\mathrm{P}_{75}\right)$ & 7.44(7.40-7.49) & 7.44(7.40-7.49) & $7.43(7.39-7.50)$ & 0.721 \\
\hline $\mathrm{pCO}_{2}(\mathrm{mmHg})$, median $\left(\mathrm{P}_{25}-\mathrm{P}_{75}\right)$ & $36.0(31.0-45.7)$ & $37.0(31.0-47.0)$ & $35.0(30.6-39.6)$ & 0.149 \\
\hline $\mathrm{pO}_{2}(\mathrm{mmHg})$, median $\left(\mathrm{P}_{25}-\mathrm{P}_{75}\right)$ & $76.1(67.0-98.4)$ & $78.0(68.0-101.5)$ & $76.0(61.0-95.7)$ & 0.152 \\
\hline Base excess, median $\left(P_{25}-P_{75}\right)$ & I.I (-2.0-5.8) & $1.8(-1.8$ to 6.0$)$ & $0.3(-3.3$ to 4.5$)$ & 0.192 \\
\hline $\mathrm{HCO}_{3}$, median $\left(\mathrm{P}_{25}-\mathrm{P}_{75}\right)$ & $25.2(22.2-30.3)$ & $25.7(22.4-30.5)$ & $24.9(21.7-28.6)$ & 0.292 \\
\hline $\mathrm{SO}_{2}$, median $\left(\mathrm{P}_{25}-\mathrm{P}_{75}\right)$ & $96.0(94.0-98.1)$ & $96.0(94.0-98.1)$ & $96.3(92.2-98.3)$ & 0.509 \\
\hline Pleural effusion, n (\%) & $26(14.4)$ & $19(13.9)$ & $7(15.9)$ & 0.737 \\
\hline \multicolumn{5}{|l|}{ Co-morbidities } \\
\hline Cardiovascular diseases, n (\%) & $21(11.6)$ & $15(10.9)$ & $6(13.6)$ & 0.628 \\
\hline Neoplasm, n (\%) & $46(25.4)$ & $24(17.5)$ & $22(50.0)$ & $<0.001 *$ \\
\hline Diabetes mellitus, $\mathrm{n}(\%)$ & $51(28.2)$ & $33(24.1)$ & $18(40.9)$ & $0.03 I^{*}$ \\
\hline Hepatic disorder, n (\%) & $13(7.2)$ & $9(6.6)$ & $4(9.1)$ & 0.392 \\
\hline Renal insufficiency, n (\%) & $31(17.1)$ & $22(16.1)$ & $9(20.5)$ & 0.501 \\
\hline \multicolumn{5}{|l|}{ PSI class } \\
\hline Class I, n (\%) & $14(7.7)$ & $13(9.5)$ & $\mathrm{I}(2.3)$ & $0.003 *$ \\
\hline Class II, n (\%) & $22(12.2)$ & $20(14.6)$ & $2(4.5)$ & \\
\hline Class III, n (\%) & $84(46.4)$ & $68(49.6)$ & $16(36.4)$ & \\
\hline Class IV, n (\%) & $48(26.5)$ & $29(21.2)$ & $19(43.2)$ & \\
\hline Class V, n (\%) & $13(7.2)$ & $7(5.1)$ & $6(13.6)$ & \\
\hline Intensive care & $28(15.5)$ & $18(64.3)$ & $10(22.7)$ & 0.126 \\
\hline \multicolumn{5}{|l|}{ Empirical antibiotics } \\
\hline Ceftazidime, n (\%) & $56(30.9)$ & $44(32.1)$ & $12(27.3)$ & 0.506 \\
\hline Ceftriaxone, n (\%) & $75(41.4)$ & $63(46.0)$ & $12(27.3)$ & \\
\hline Levofloxacin, n (\%) & $20(11.0)$ & $15(10.9)$ & $5(11.4)$ & \\
\hline Ceftazidime + levofloxacin, n (\%) & $16(8.8)$ & $9(6.6)$ & $7(15.9)$ & \\
\hline Ceftriaxone + levofloxacin, n (\%) & $14(7.7)$ & $6(4.4)$ & $8(18.2)$ & \\
\hline \multicolumn{5}{|l|}{ Clinical follow-up } \\
\hline Length of stay, median $\left(P_{25}-P_{75}\right)$ & $12.0(8.0-16.0)$ & $11.5(8.0-15.8)$ & $12.6(9.0-16.4)$ & 0.374 \\
\hline Day-3 improvement, n (\%) & $81(44.8)$ & $76(55.5)$ & $5(11.4)$ & $<0.001 *$ \\
\hline 14-day mortality rates, n (\%) & $55(30.4)$ & $30(21.9)$ & $25(56.8)$ & $<0.001 *$ \\
\hline
\end{tabular}

Note: *Statistically significant, $p$-value $<0.05$.

Abbreviations: DBP, diastolic blood pressure; max, maximum; med, median; min, minimum; MDR, multidrug-resistant; PSI, pneumonia severity index; RR, respiratory rate; SBP, systolic blood pressure. 
Table 5 Multivariate Analysis Of Risk Factors For Mortality Among CAP Patients

\begin{tabular}{|c|c|c|c|c|c|c|c|c|}
\hline \multirow[t]{2}{*}{ Variable } & \multicolumn{2}{|c|}{ CAP Mortality } & \multicolumn{3}{|c|}{ Univariate Analysis } & \multicolumn{3}{|c|}{ Multivariate Analysis } \\
\hline & No $(n=\mid 26)$ & Yes $(n=55)$ & OR & $95 \% \mathrm{Cl}$ & p-value & aOR & $95 \% \mathrm{Cl}$ & p-value \\
\hline \multicolumn{9}{|l|}{ Host factors } \\
\hline Male & $82(65.1)$ & $35(63.6)$ & 0.939 & $0.485-1.817$ & 0.852 & 0.483 & $0.190-1.229$ & 0.127 \\
\hline Age $>60$ & $40(3 \mid .7)$ & $26(47.3)$ & 1.928 & $1.008-3.688$ & 0.047 & 1.482 & $0.585-3.751$ & 0.407 \\
\hline Cardiovascular disease & $9(7.1)$ & $\mid 2(2 \mid .8)$ & 3.628 & $1.428-9.216$ & 0.007 & 2.401 & $0.684-8.422$ & 0.171 \\
\hline Neoplasm & $21(16.7)$ & $25(45.5)$ & 4.167 & $2.053-8.458$ & $<0.001$ & $2.755^{*}$ & $1.03|-7.36|$ & 0.043 \\
\hline Diabetes mellitus & $24(19.0)$ & $27(49.1)$ & 4.098 & $2.054-8.177$ & $<0.001$ & 2.098 & $0.780-5.642$ & 0.142 \\
\hline Liver disease & $7(5.6)$ & $6(10.9)$ & 2.082 & $0.666-6.509$ & 0.208 & 3.800 & $0.633-22.810$ & 0.144 \\
\hline Renal insufficiency & $18(14.3)$ & $13(23.6)$ & 1.857 & $0.837-4.123$ & 0.128 & 1.917 & $0.592-6.201$ & 0.277 \\
\hline PSI class $\geq 3$ & $92(73.0)$ & $53(96.4)$ & 9.793 & $2.262-42.407$ & 0.002 & $9.188 *$ & $|.510-55.89|$ & 0.016 \\
\hline Day-3 improvement & $77(61.1)$ & $4(7.3)$ & 0.050 & $0.017-0.147$ & $<0.001$ & $0.055^{*}$ & $0.016-0.190$ & $<0.001$ \\
\hline \multicolumn{9}{|l|}{ Agent factor } \\
\hline MDR-bacterial infections & $19(15.1)$ & $25(45.5)$ & 4.693 & $2.282-9.651$ & $<0.001$ & 1.259 & $0.47|-3.36|$ & 0.646 \\
\hline \multicolumn{9}{|l|}{ Treatment factor } \\
\hline Antibiotic combination & |4(II.I) & $16(29.1)$ & 3.282 & $1.468-7.338$ & 0.004 & 2.424 & $0.717-8.196$ & 0.154 \\
\hline
\end{tabular}

Note: *Statistically significant in multivariate analysis, the aOR C195\% does not include a value of I.

Abbreviations: CAP, community-acquired pneumonia; MDR, multidrug resistance; OR, odds ratio; aOR, adjusted odds ratio; PSI, pneumonia severity index.

Methicillin-resistant Staphylococcus aureus (MRSA). ${ }^{40}$ Community-acquired MRSA (CA-MRSA) has emerged as an important pathogen for CAP. In several hospitals in Indonesia, an identification test of MRSA for pneumonia patients has not been routinely conducted considering the cost and the results of a previous study reporting the low prevalence of CA-MRSA among patients admitted to the hospital. ${ }^{41}$

We identified $A$. baumannii as a causative agent for CAP with high antimicrobial resistance. GNB has been determined as the dominant pathogen causing CAP in Indonesia and other countries of Asia. ${ }^{30,31,42}$ Outbreaks of A. baumannii are currently responsible for community and nosocomialinfectious diseases such as in South Asia where the species has been observed as a cause of pneumonia since $1989 .{ }^{43}$ Acinetobacter species are commonly encountered as colonizing organisms in the upper-respiratory and gastrointestinal tracts. ${ }^{44}$ Therefore, MDR Acinetobacter is problematic, especially in immunocompromised hosts. Of 28 Acinetobacter infections in our study, around $60 \%$ were highly resistant to ciprofloxacin. Similarly, the results from a previous study investigated the resistance mechanism of 75 Acinetobacter species from Walter Reed Army Medical Center (WRAMC). Among the respiratory specimens, $80 \%$ of isolates were identified as being resistant to ciprofloxacin and cefepime. ${ }^{45}$ In addition, we found that $E$. coli had poor sensitivity to penicillins. Most of the isolates were highly sensitive to third-generation cephalosporins, fluoroquinolones, and carbapenems. A previous study in Indonesia found that $8 \%$ of $E$. coli were resistant to ciprofloxacin commonly through independent selection among resistant mutants. ${ }^{46}$ Notably, $K$. pneumoniae presented as the highest prevalent GNB in 7 Asian countries with a low resistance rate to cefuroxime and ceftriaxone. ${ }^{47} \mathrm{~K}$. pneumoniae in Indonesia should be considered as a threat for potential outbreaks as $15 \%$ of adults, and $7 \%$ of children tested carried this organism. ${ }^{48}$ Previous evidence regarding CAP etiology in Semarang, the sixth biggest city in Indonesia, has reported results in line with this study. The study found that the prevalence of $K$. pneumonia was the most commonly identified among bacteria causing CAP. MDR K. pneumoniae, E. coli, and Enterobacter spp. expressed extended-spectrum b-lactamases (ESBLs). These enzymes inactivate penicillins and cephalosporins leading to limited treatment options with currently available antimicrobial agents. ${ }^{24}$

The clinical relevance of GNB findings from respiratory specimens among pneumonia patients is usually debated as it might reflect colonization rather than pulmonary infection. Low awareness of infection prevention and high transmission between patients and the community is challenging in LMICs. The prevalence of GNB is lower in some regions especially in Europe, the US, and Canada except in the context of hospital-acquired pneumonia; ${ }^{49-51}$ notably different from reports from Asian countries, as reflected by recommendations made by the ATS and BTS in their respective guidelines. ${ }^{3,5,47}$ 
The crucial concern of CAP management in most guidelines is $P$. aeruginosa infection, which carries a poor prognosis and high mortality. ${ }^{2,3,5,20}$ In our study, $P$. aeruginosa remained sensitive to anti-pseudomonal $\beta$-lactam antibiotics such as ceftazidime and cefoperazone. Comparing our results with other LMICs, our findings were similar to a Nigerian study on 232 pneumonia patients with $77 \%$ and $75.5 \%$ having isolates sensitive to ceftazidime and levofloxacin, respectively. ${ }^{52}$ For Egypt, a study on CAP revealed that $P$. aeruginosa had the highest resistance to levofloxacin (56.5\%) followed by ciprofloxacin and piperacillin/tazobactam which rated at $47.8 \% .^{53}$

Malignancy as an underlying disease was earlier reported to be associated with high mortality (27\%) among CAP patients. ${ }^{54}$ Neoplastic disease is scored +30 in the PSI scoring system. ${ }^{24}$ A prediction value of PSI has been used widely to estimate mortality. PSI class III or above indicates that the risk of death is high, and the patients need hospitalization. We used PSI categorization since this system includes 19 comprehensive aspects. According to ATS/IDSA guidelines, patients started on empirical antimicrobial therapy who show clinical improvement within the first three days could safely be switched from intravenous to oral antibiotics. ${ }^{3,55}$ In our study, we explored whether the day-3 evaluation would be a critical time point to evaluate the efficacy of empirical treatment and to estimate patients' risk of mortality. An assessment of clinical response at day 4 of patients with community-acquired bacterial pneumonia (CABP) was also suggested by the Food and Drug Administration (FDA) guidance. ${ }^{56}$ In line, our findings recommend a combination assessment of clinical response in the first three days as an additional value to PSI scoring where both assessments were investigated as independent risk factors for mortality among patients with pneumonia. Moreover, the successful treatment response to empirical treatment could help to switch to oral antimicrobial treatment on day 3, with additional information that will then be available from culture and susceptibility data from the Microbiology Laboratory.

Despite the results obtained in the study, there were several limitations. First, only patients with a positive culture were included. Thus the results may not be representative for all patients especially those in whom culturing was either not tried, or failed to yield causative organisms. Second, we did not include antibiotics given after culture results became available especially in critically ill patients where the selection of antimicrobial drugs and the dosages may have impacted on the clinical outcomes, including mortality. Third, we conducted the study at a single center, albeit a large hospital in Indonesia; extrapolation of our results needs confirmation in other centers on Java or even Indonesia and beyond. Forth, our exclusion of patients who died within 24 hrs might have caused bias, with the most severely ill patients potentially having an early fatal outcome. Notwithstanding, in the absence of a specified and verified diagnosis, valid inclusion seemed impossible. A further limitation of our study concerns the fact that it is not impossible that some CAP diagnoses were misclassified hospital-/ventilator-acquired pneumonia. Given the involvement of the pulmonologist in specifying and verifying the diagnosis in an early stage, we do not expect many (or even any) misclassifications in this respect.

However, the study provides updated information about the local pattern of resistance to antimicrobials among MDR-CAP. The presence of MDR organisms in the community is an indicator of the complex hindrances faced in the implementation of the national health system. Besides high transmission of pathogens in the tropical environment, the free access to antibiotics in the community among LMICs could be the main cause of MDR.

The study supports the notion that the use of antibiotics in the community urgently needs to be restricted to control the emergence of further resistance. Private sectors and governments need to monitor the pattern of pathogens and the resistance to antibiotics regularly. Our report adds important information needed to select empirical antimicrobial treatment for CAP, including the coverage of GNB infections for LMICs like Indonesia.

\section{Conclusion}

S. pneumoniae was the predominant pathogen of hospitalized CAP. GNB were common as well, and these organisms should likewise be considered and covered in empirical treatment. A. baumannii and K. pneumoniae were common and carried a high risk for MDR-CAP. Concerning the implementation of the local guideline where $\beta$-lactam antibiotics are used for empirical treatments in CAP patients, the pathogens generally remain highly susceptible to the third-generation cephalosporins. Rapid and advanced microbiological diagnostics are required to monitor further drug resistance emergence and to ensure that empirical therapy remains effective for CAP. This data should be incorporated in the design for local guidelines for empirical treatment of CAP. Eventually, we recommend assessing clinical response to therapy within the first three 
days follow up as this has an important prognostic value that adds to the PSI scoring system and microbiological evaluation.

\section{Acknowledgments}

The work was supported by a Directorate General of Higher Education (DIKTI), Ministry of Research, Technology and Higher Education of the Republic of Indonesia [No.224/ D3.2/PG/2016].

\section{Author contributions}

All authors contributed to data analysis, drafting and revising the article, gave final approval of the version to be published, and agree to be accountable for all aspects of the work.

\section{Disclosure}

Professor Maarten J. Postma received grants and honoraria from various pharmaceutical companies, all unrelated to this research except one Advisory Board (Pfizer) on the Staphylococcus aureus vaccine to prevent surgical site infections. The other authors report no conflicts of interests in this work.

\section{References}

1. Anevlavis S, Bouros D. Community acquired bacterial pneumonia. Expert Opin Pharmacother. 2010;11(3):361-374.

2. Eccles S, Pincus C, Higgins B, et al. Diagnosis and management of community and hospital acquired pneumonia in adults: summary of NICE guidance. BMJ. 2014;349:1-5.

3. Mandell LA, Wunderink RG, Anzueto A, et al. Infectious diseases society of America/American Thoracic Society consensus guidelines on the management of community-acquired pneumonia in adults. Clin Infect Dis. 2007;44(Suppl 2):S27-S72.

4. Woodhead M. New guidelines for the management of adult lower respiratory tract infections. Eur Respir J. 2011;38(6):1250-1251.

5. Lim WS, Baudouin SV, George RC, et al. BTS guidelines for the management of community acquired pneumonia in adults: update 2009. Thorax. 2009;64(Suppl 3):iii1-iii55.

6. Arnold FW, Wiemken TL, Peyrani P, Ramirez JA, Brock GN. Mortality differences among hospitalized patients with communityacquired pneumonia in three world regions: results from the community-acquired pneumonia organization (CAPO) International cohort study. Respir Med. 2013;107(7):1101-1111.

7. National report of basic health research (Laporan nasional Riskesdas 2018), Ministry of Health, Republic of Indonesia. 2018. Available from: http://labdata.litbang.depkes.go.id/riset-badan-litbangkes/menuriskesnas/menu-riskesdas/426-rkd-2018. Accessed September 12, 2019.

8. Ministry of Health, Republic of Indonesia, Basic health research (Riskesdas 2013). 2013. Available from: http://labdata.litbang.depkes. go.id/riset-badan-litbangkes/menu-riskesnas/menu-riskesdas/374-rkd2013. Accessed September 12, 2019.

9. File TM. Community-acquired pneumonia. Lancet (London, England). 2003;362(9400):1991-2001.
10. Rodrigo-Troyano A, Sibila O. The respiratory threat posed by multidrug resistant Gram-negative bacteria. Respirology. 2017;22 (7):1288-1299.

11. Padget M, Guillemot D, Delarocque-Astagneau E. Measuring antibiotic consumption in low-income countries: a systematic review and integrative approach. Int J Antimicrob Agents. 2016;48(1):27-32.

12. World Health Organization. Antimicrobial resistance: global report on surveillance. 2014. Available from: https://apps.who.int/iris/bitstream/han dle/10665/112642/9789241564748_eng.pdf. Accessed September 24, 2019.

13. de Kraker MEA, Wolkewitz M, Davey PG, et al. Burden of antimicrobial resistance in European hospitals: excess mortality and length of hospital stay associated with bloodstream infections due to Escherichia coli resistant to third-generation cephalosporins. $J$ Antimicrob Chemother. 2011;66(2):398-407.

14. de Kraker MEA, Davey PG, Grundmann H. Mortality and hospital stay associated with resistant Staphylococcus aureus and Escherichia coli bacteremia: estimating the burden of antibiotic resistance in Europe. PLoS Med. 2011;8(10):e1001104.

15. van Hecke O, Wang K, Lee JJ, Roberts NW, Butler CC. Implications of antibiotic resistance for patients' recovery from common infections in the community: a systematic review and meta-analysis. Clin Infect Dis. 2017;65(3):371-382.

16. Ong CWM, Lye DCB, Khoo KL, et al. Severe community-acquired Acinetobacter baumannii pneumonia: an emerging highly lethal infectious disease in the Asia-Pacific. Respirology. 2009;14(8):1200-1205.

17. Mohd R, Nesam T, Kamaruzaman L, Cader RA, Mustafar R, Kong W-Y. Community acquired multi drug resistant (MDR) Acinetobacter baumannii pneumonia in Malaysia - A case report. Respir Med Case Rep. 2018;24:147-149.

18. Peng C, Zong Z, Fan H. Acinetobacter baumannii isolates associated with community-acquired pneumonia in West China. Clin Microbiol Infect. 2012;18(12):E491-3.

19. Ethical principles for medical research involving human subjects version 2013. 64th World Medical Association General Assembly, Fortaleza, Brazil, October 2013. Available from: https://www.wma.net/ policies-post/wma-declaration-of-helsinki-ethical-principles-for-medi cal-research-involving-human-subjects/. Accessed July 11, 2019.

20. Adapted from Indonesian Society of Respirology. Guideline for diagnosis and man-agement of community pneumonia in Indonesia [Perhimpunan Dokter Paru Indonesia. Pneumonia komuniti: pedoman diagnosis \& penatalaksanaan di Indonesia] 2003, page 13. Available from: http://www.klikpdpi.com/konsensus/konsensus-pneumonia kom/pnkomuniti.pdf. Accessed October 7, 2019.

21. Roson B, Carratala J, Verdaguer R, Dorca J, Manresa F, Gudiol F. Prospective study of the usefulness of sputum Gram stain in the initial approach to community-acquired pneumonia requiring hospitalization. Clin Infect Dis. 2000;31(4):869-874.

22. Magiorakos A-P, Srinivasan A, Carey RB, et al. Multidrug-resistant, extensively drug-resistant and pandrug-resistant bacteria: an international expert proposal for interim standard definitions for acquired resistance. Clin Microbiol Infect. 2012;18(3):268-281.

23. Clinical and Laboratory Standards Institute. Available from: https:// clsi.org/. Accessed May 24, 2019

24. Fine MJ, Auble TE, Yealy DM, et al. A prediction rule to identify low-risk patients with community-acquired pneumonia. $N$ Engl J Med. 1997;336 (4):243-250.

25. Holter JC, Ueland T, Jenum PA, et al. Risk factors for long-term mortality after hospitalization for community-acquired pneumonia: a 5-year prospective follow-up study. PLoS One. 2016;11(2):e0148741.

26. Luna CM, Palma I, Niederman MS, et al. The impact of age and comorbidities on the mortality of patients of different age groups admitted with community-acquired pneumonia. Ann Am Thorac Soc. 2016;13(9):15191526 . 
27. Harris AM, Bramley AM, Jain S, et al. Influence of antibiotics on the detection of bacteria by culture-based and culture-independent diagnostic tests in patients hospitalized with community-acquired pneumonia. Open Forum Infect Dis. 2017;4(1). DOI:10.1093/OFID/OFX014

28. Miyashita N, Shimizu H, Ouchi K, et al. Assessment of the usefulness of sputum Gram stain and culture for diagnosis of community-acquired pneumonia requiring hospitalization. Med Sci Monit. 2008;14(4): CR171-6.

29. Hung IF-N, Tantawichien T, Tsai YH, Patil S, Zotomayor R. Regional epidemiology of invasive pneumococcal disease in Asian adults: epidemiology, disease burden, serotype distribution, and antimicrobial resistance patterns and prevention. Int J Infect Dis. 2013;17(6):e364-73.

30. Peto L, Nadjm B, Horby P, et al. The bacterial aetiology of adult community-acquired pneumonia in Asia: a systematic review. Trans R Soc Trop Med Hyg. 2014;108(6):326-337.

31. Goyet S, Vlieghe E, Kumar V, et al. Etiologies and resistance profiles of bacterial community-acquired pneumonia in Cambodian and neighboring countries' health care settings: a systematic review (1995 to 2012). PLoS One. 2014;9(3):e89637.

32. Ergin A, Köseog Ö. Erythromycin and penicillin resistance mechanisms among viridans group streptococci isolated from blood cultures of adult patients with underlying diseases. New Microbiol. 2011; 34:187-193.

33. Hakenbeck R, Brückner R, Denapaite D, Maurer P. Molecular mechanisms of $\mathrm{b}$-lactam resistance in Streptococcus pneumoniae. Future Microbiology. 2012;7(3)395-410. doi:10.2217/fmb.12.2

34. Cornick JE, Bentley SD. Streptococcus pneumoniae: the evolution of antimicrobial resistance to beta-lactams, fluoroquinolones and macrolides. Microbes Infect. 2012;14(7-8):573-583.

35. Stinson MW, Alder S, Kumar S. Invasion and killing of human endothelial cells by viridans group streptococci. Infect Immun. 2003;71(5):2365-2372.

36. Bochud PY, Calandra T, Francioli P. Bacteremia due to viridans streptococci in neutropenic patients: a review. Am J Med. 1994;97 (3):256-264.

37. Choi SH, Cha S-I, Choi K-J, et al. Clinical characteristics of community-acquired viridans streptococcal pneumonia. Tuberc Respir Dis (Seoul). 2015;78(3):196-202.

38. Shinzato T, Saito A. The Streptococcus milleri group as a cause of pulmonary infections. Clin Infect Dis. 1995;21(Suppl 3):S238-43.

39. Waitkins SA, Ratcliffe JG, Roberts C. Streptococcus milleri found in pulmonary empyemas and abscesses. J Clin Pathol. 1985;38(6):716-717.

40. Shore AC, Deasy EC, Slickers P, et al. Detection of staphylococcal cassette chromosome mec type XI carrying highly divergent mecA, mecI, mecR1, blaZ, and ccr genes in human clinical isolates of clonal complex 130 methicillin-resistant Staphylococcus aureus. Antimicrob Agents Chemother. 2011;55(8):3765-3773.

41. Centers for Disease Control and Prevention (CDC). Severe methicillin-resistant Staphylococcus aureus community-acquired pneumonia associated with influenza-louisiana and Georgia, December 2006January 2007. MMWR Morb Mortal Wkly Rep. 2007;56(14):325-329.

42. Farida H, Gasem MH, Suryanto A, et al. Viruses and Gram-negative bacilli dominate the etiology of community-acquired pneumonia in Indonesia, a cohort study. Int J Infect Dis. 2015;38:101-107.
43. Krisanapan S, Naphathorn P, Kaewprom P. Community acquired Acinetobacter pneumonia: report of two cases. Southeast Asian J Trop Med Public Health. 1989;20(3):497-498.

44. Allen DM, Hartman BJ. Acinetobacter species. In: Mandell GL, Bennett JE, Dolin R, editors. Mandell, Douglas and Bennett's Principles and Practice of Infectious Disease. 6th ed. Philadelphia: Elsevier Churchill Livingstone; 2005. p. 2632.

45. Hujer KM, Hujer AM, Hulten EA, et al. Analysis of antibiotic resistance genes in multidrug-resistant Acinetobacter sp. isolates from military and civilian patients treated at the walter reed army medical center. Antimicrob Agents Chemother. 2006;50(12):41144123.

46. Kuntaman K, Lestari ES, Severin JA, et al. Fluoroquinolone-resistant Escherichia coli, Indonesia. Emerg Infect Dis. 2005;11(9):13631369.

47. Song JH, Oh WS, Kang CI, et al. Epidemiology and clinical outcomes of community-acquired pneumonia in adult patients in Asian countries: a prospective study by the Asian network for surveillance of resistant pathogens. Int J Antimicrob Agents. 2008;31(2):107-114.

48. Farida H, Severin JA, Gasem MH, et al. Nasopharyngeal carriage of Klebsiella pneumoniae and other Gram-negative bacilli in pneumonia-prone age groups in Semarang, Indonesia. J Clin Microbiol. 2013;51(5):1614-1616.

49. Hyllienmark P, Martling C-R, Struwe J, Petersson J. Pathogens in the lower respiratory tract of intensive care unit patients: impact of duration of hospital care and mechanical ventilation. Scand J Infect Dis. 2012;44(6):444-452.

50. Papan C, Meyer-Buehn M, Laniado G, Nicolai T, Griese M, Huebner J. Assessment of the multiplex PCR-based assay Unyvero pneumonia application for detection of bacterial pathogens and antibiotic resistance genes in children and neonates. Infection. 2018;46(2):189-196.

51. Verhamme KMC, De Coster W, De Roo L, et al. Pathogens in earlyonset and late-onset intensive care unit-acquired pneumonia. Infect Control Hosp Epidemiol. 2007;28(4):389-397.

52. Iroezindu MO, Chima EI, Isiguzo GC, et al. Sputum bacteriology and antibiotic sensitivity patterns of community-acquired pneumonia in hospitalized adult patients in Nigeria: a 5-year multicentre retrospective study. Scand J Infect Dis. 2014;46(12):875-887.

53. Resistance D. Community acquired pneumonia among adult patients at an Egyptian university hospital : bacterial etiology, susceptibility profile and evaluation of the response to initial empiric antibiotic therapy. infect Drug Resist. 2018;11:2141-2150.

54. Bruns AHW, Oosterheert JJ, Cucciolillo MC, et al. Cause-specific long-term mortality rates in patients recovered from communityacquired pneumonia as compared with the general Dutch population. Clin Microbiol Infect. 2011;17(5):763-768.

55. Ramirez JA, Srinath L, Ahkee S, Huang A, Raff MJ. Early switch from intravenous to oral cephalosporins in the treatment of hospitalized patients with community-acquired pneumonia. Arch Intern Med. 1995;155(12):1273-1276.

56. Eckburg PB, Friedland HD, Llorens L, et al. Day 4 clinical response of Ceftaroline Fosamil Versus Ceftriaxone for community-acquired bacterial Pneumonia. Infect Dis Clin Pract. 2012;20(4):254-260. 


\section{Video abstract}

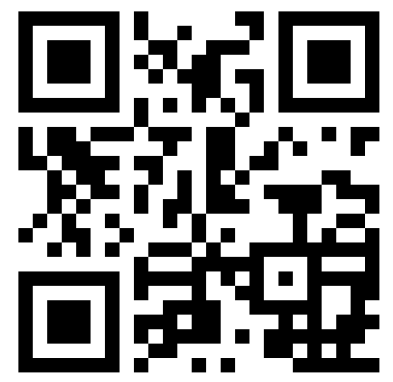

Point your SmartPhone at the code above. If you have a QR code reader the video abstract will appear. Or use: https://youtu.be/QzMq278Mac

\section{Publish your work in this journal}

Infection and Drug Resistance is an international, peer-reviewed openaccess journal that focuses on the optimal treatment of infection (bacterial, fungal and viral) and the development and institution of preventive strategies to minimize the development and spread of resistance. The journal is specifically concerned with the epidemiology of antibiotic resistance and the mechanisms of resistance development and diffusion in both hospitals and the community. The manuscript management system is completely online and includes a very quick and fair peerreview system, which is all easy to use. Visit http://www.dovepress.com/ testimonials.php to read real quotes from published authors. 